\title{
STABILITY ASSESSMENT OF ROCK SLOPES FROM RANAU, SABAH USING MODIFIED D-SLOPE METHOD
}

\author{
Hennie Fitria Wulandary Soehady Erfen ${ }^{1,2 *}$, Aiman Nabila Abdul Malik ${ }^{1}$ \\ 1 Geology Program, Faculty of Science and Natural Resources, Universiti Malaysia Sabah \\ ${ }^{2}$ Natural Disaster Research Centre (NDRC), Universiti Malaysia Sabah \\ *Corresponding Author E-mail: henniefs@ums.edu.my
}

This is an open access article distributed under the Creative Commons Attribution License, which permits unrestricted use, distribution, and reproduction in any medium, provided the original work is properly cited.

\section{ARTICLE DETAILS}

\section{Article History:}

Received 26 June 2018 Accepted 2 July 2018

Available online 1 August 2018

\section{ABSTRACT}

An assessment of stability potential of rock slopes from Ranau, Sabah has been conducted using modified D-slope method. D-slope comprises of G-Rating determination and Potential Instability to assess the slope condition using field observations, laboratory analysis and microfabric analysis. 17 parameters have been done for G-Rating purpose including the type of rocks, weathering grade, existence of faults and joints, number of major sets, number of orientations, aperture, persistence and spacing of discontinuities, rainfall, hydraulic condition, height of slope, history of instability, porosity, strength, micro-petrographic and micro-fractures index. Kinematic analysis is used for Potential Instability analysis to determine the type of failures for each slope. This later is to determine the level of slope's risk: No Risk, Low Risk, Moderate Risk or High Risk. Six slopes have been chosen from Trusmadi Formation and ultrabasic Rocks along Marakau - Ranau Sport Complex. Based on the results of G-Rating, only slope S1 and S4 have value more than 0.4 while other slopes have less than 0.4 which indicates stable slopes. Based on kinematic analysis, all slopes experienced wedge failures with S4 and S5 also have planar failure possibility which show that all slopes have potential instability. D-slope analysis indicates that slope S4 is considered as Moderate Risk with mitigation suggestions are rock anchor and soil nailing with further actions required. Slope S1 is categorized as Low Risk with suggestions of stream system inspection and vegetation on exposed area of the slopes, while other slopes (S2, S3, S5 and S6) have no suggestion for mitigation as been assessed as No Risk.

\section{KEYWORDS}

D-slope method, laboratory analysis and microfabric analysis, Trusmadi Formation, G-Rating, Potential Instability.

\begin{abstract}
1.INTRODUCTION
Slope failures are considered as common disaster which is frequently occurred. This geodisaster is related to infrastructure development such as highways, roads and dams. The failure basically is influenced by several factors such as water retention and the existence of discontinuities. When the slope is steeper than its gravity which holds the load to stay put, slope failure can happened [1]. It is controlled by discontinuities which reduce the shear strength of the slope [2, 3]. This condition accelerates weathering process which decreases the rock's strength and increase the number and aperture of fractures. The increment of fractures resulted to higher porosity with smaller distance of each set of fractures [4].
\end{abstract}

D-Slope system is introduced as a method to assess the rock slope stability [5]. The system is consists of suitable method to make stability assessment by using geological, geotechnical and hydrogeology data which obtained from field studies. From these data, risk hazard value (G-Rating) can be determined. The system also used kinematic analysis and discontinuities survey for Potential Instability (PI) which then combined with G-Rating value, can classify the slope as No Risk, Medium Risk, Medium Risk and High Risk. Since the system is based on 13 parameters from field data, the mechanical properties such as porosity and strength of rock of the slope also are considered for peer assessment. Microfabric analysis also been conducted to determine the micro-petrography and micro-fractures index of the rocks. These additional four (4) parameters have been included in modified D-Slope system to seek internal properties of slope's material which also play important roles in determine the slope's instability potential.

The study area is located at Marakau - Ranau Sport Complex area, Ranau district, Sabah which is bounded by $5^{\circ} 55^{\prime} \mathrm{N}-6^{\circ} 00^{\prime} \mathrm{N}$ and $116^{\circ} 39^{\prime} \mathrm{E}-116^{\circ}$ $45^{\prime} \mathrm{E}$ (Figure 1). The study area consists of ultrabasic rocks which mostly are serpentinised peridotite as part of ophiolite complex (Cretaceous age), Trusmadi Formation aged Paleocene to Late Eocene, Crocker Formation (Late Eocene - Middle Miocene) and Quaternary- aged Pinosouk Gravel and alluvium deposition. Trusmadi Formation is divided into four types namely argillite, turbidite, breccia and massive sandstones while serpentinised peridotite formed due to serpentinisation which change olivine minerals in peridotite to serpentinite [6].

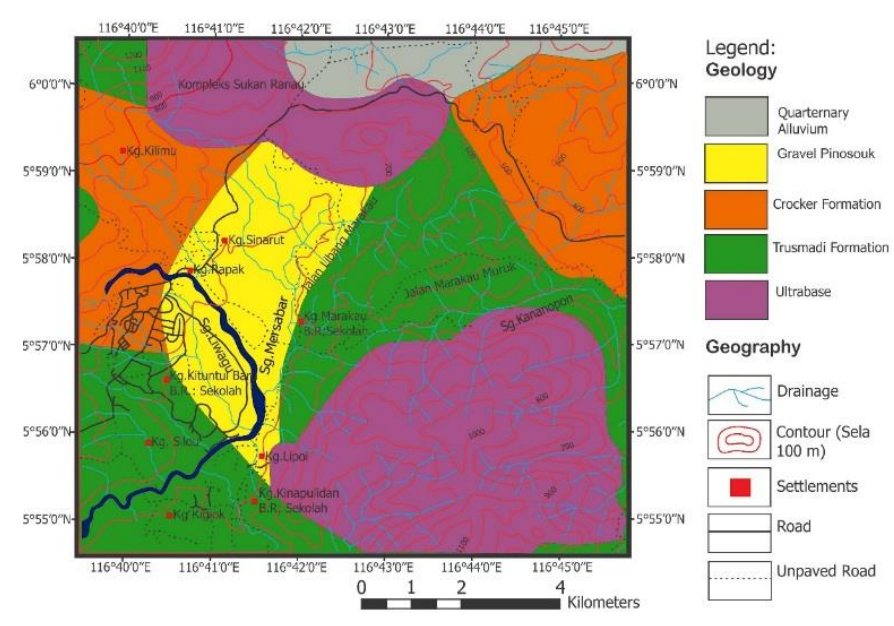

Figure 1: Geological map of the study area

\section{MATERIALS AND METHODOLOGY}

Previous research has been conducted in the early study to understand the 
study area and related methodology to be used for this study. Base map and geological maps are produced before fieldworks started. Base map contains geographical information such as stream, topography and transportation system while the geological map shows the distribution and boundary of rock units in the study area. Fieldwork is crucial in this study to obtain detailed information on the study area including slope observation. Six (6) rock slopes are selected from Trusmadi Formation and ultrabasic rocks to be observed on field based on D-Slope assessment system. Rock samples from each slope also are collected for laboratory analysis purposes.

There are two parts in D-Slope system which is the G-Rating value determination and Potential Instability (PI) analysis [5]. Thirteen (13) parameters are set to be observed on field based on geological parameters (type of rocks, weathering grade, existence of faults and joints, number of major sets, number of orientations, aperture, persistence and spacing of discontinuities), hydrogeological parameters (rain and hydraulic condition) and slope characterization (height of slope and history of instability).

Additional parameters to assess the slope stability are set through laboratory analysis which includes porosity, strength, micro-petrography and micro-fractures of slope rocks. Microfabric analysis is also conducted in this study to determine the micro-petrography and micro-fractures index of rocks by using thin section and scanning electron microscope
(SEM). Micro-petrography index is determined by the ratio of primary mineral to secondary minerals, while micro-fractures index is to determine the number of microfractures presence along $1 \mathrm{~mm}$ in the rock's thin section. The presence of secondary minerals and the higher number of microfractures show the low strength of rocks which affects to slope stability. The porosity and trength analysis are carried out based in International Standard of Rock Mechanics (ISRM) where porosity analysis is to determine the percentage of pores through calculation of voids over total volume of rocks [7]. Meanwhile strength analysis is conducted using point load test where the samples are been cut into cubic size and place in between two vertical cones before the stress is applied. These four (4) additional parameter is added to observe the internal condition of the slope by testing the rock materials.

Therefore, there are 17 parameters of slope characteristics to be observed internally and externally to assess the slope stability. Each parameter consists of rating value from 0 (minimum) to 2 (maximum) (Table 1). All values obtained then been added before divide it with the maximum value of all parameters (Formula 1).

$$
\text { G-Rating }=\Sigma \mathrm{R}_{\mathrm{i}} / \Sigma \mathrm{R}_{\max } \text { (Formula 1) }
$$

Where:

$\Sigma R_{\mathrm{i}} \quad=$ Total of each parameter's rating value

$\Sigma \mathrm{R}_{\max }=$ Total of maximum rating value of all parameters

Table 1: Modified parameter used for G-rating determination

\begin{tabular}{|c|c|c|}
\hline Parameters & Remarks & Rating Value \\
\hline \multirow{3}{*}{ 1. Geology } & Igneous Rocks & 0 \\
\hline & Metamorphic Rocks & 1 \\
\hline & Sedimentary Rocks & 2 \\
\hline \multirow{3}{*}{ 2. Weathering Grade } & $1-2$ & 0 \\
\hline & $3-4$ & 1 \\
\hline & $5-6$ & 2 \\
\hline \multirow{3}{*}{ 3. Faults } & None & 0 \\
\hline & Minor & 1 \\
\hline & Major & 2 \\
\hline \multirow{3}{*}{ 4. Joints } & Minor & 0 \\
\hline & Major & 1 \\
\hline & Too Many & 2 \\
\hline \multirow{3}{*}{ 5. Number of Major Sets } & $<2$ & 0 \\
\hline & $3-4$ & 1 \\
\hline & $>4$ & 2 \\
\hline \multirow{3}{*}{ 6. Number of Orientation } & $<2$ & 0 \\
\hline & $3-4$ & 1 \\
\hline & $>4$ & 2 \\
\hline \multirow{3}{*}{ 7. Apertures (mm) } & $<2$ & 0 \\
\hline & $2-4$ & 1 \\
\hline & $>5$ & $\frac{1}{2}$ \\
\hline \multirow{3}{*}{ 8. Persistence $(\mathrm{m})$} & $<4$ & 0 \\
\hline & $4-10$ & 1 \\
\hline & $>10$ & 2 \\
\hline \multirow{3}{*}{ 9. Spacing $(\mathrm{mm})$} & $<200$ & 0 \\
\hline & $201-2000$ & 1 \\
\hline & $>2000$ & 2 \\
\hline \multirow{3}{*}{ 10. Slope Height } & $<5$ & 0 \\
\hline & $5-15$ & 1 \\
\hline & $>15$ & 2 \\
\hline \multirow{3}{*}{ 11. Instability History } & No proof & 0 \\
\hline & $\begin{array}{l}\text { Fragments of smaller rocks on the side } \\
\text { of the slope }\end{array}$ & 1 \\
\hline & Rock falls (Major/Minor) $50 \mathrm{~m}^{3}$ & 2 \\
\hline \multirow{3}{*}{ 12. Rainfall (mm/month) } & $<100$ & 0 \\
\hline & $101-300$ & 1 \\
\hline & $>300$ & 2 \\
\hline \multirow{3}{*}{ 13. Hydraulic Condition } & Dry & 0 \\
\hline & Damp & 1 \\
\hline & Dripping - flowing & 2 \\
\hline \multirow{3}{*}{ 14. Micro-petrography Index, Imp } & $>12$ & 0 \\
\hline & $2-12$ & 1 \\
\hline & $<0.5-2$ & 2 \\
\hline \multirow{2}{*}{ 15. Micro-fractures Index, Ifr } & $<0.5-2$ & 0 \\
\hline & $2-10$ & 1 \\
\hline
\end{tabular}




\begin{tabular}{|l|l|l|}
\hline & $>10$ & 2 \\
\hline \multirow{3}{*}{$16 . \quad$ Porosity (\%) } & $<15$ & 0 \\
\cline { 2 - 3 } & $15-30$ & 1 \\
\cline { 2 - 3 } & $>30$ & 2 \\
\hline \multirow{3}{*}{ 17. Strength (MPa) } & \multicolumn{1}{|c|}{$>100$} & 0 \\
\cline { 2 - 3 } & $12.5-100$ & 1 \\
\cline { 2 - 3 } & $<12.5$ & 2 \\
\hline
\end{tabular}

Meanwhile Potential Instability analysis is based on the survey of discontinuities to determine failure type that occurred on slope (kinematic analysis). This analysis refers to slope's potential to fail with the existence of wedge, planar and/or toppling failure. If there is no failure detected, thus there is no instability potential (Table 2).

Table 2: Relation between slope failures with instability potential

\begin{tabular}{|l|l|}
\hline Type of Failure & Instability Potential \\
\hline None & No \\
\hline Rotational Failure & Yes \\
\hline Planar Failure & Yes \\
\hline Wedge Failure & Yes \\
\hline Toppling Failure & Yes \\
\hline
\end{tabular}

By combining both G-Rating value and PI analysis, the risk or stability of the slope can be assess and estimated. Level of risk is divided into four which are: Low Risk, Less Risk, Medium Risk and High Risk (Table 2).

Table 2: Classification of risk for rock slopes [8]

\begin{tabular}{|c|c|c|c|}
\hline Classification & G-Rating & $\begin{array}{l}\text { Instability } \\
\text { Potential }\end{array}$ & Risk Level \\
\hline \multirow{2}{*}{ I } & \multirow{2}{*}{$<0.4$} & Yes & No Risk \\
\hline & & No & No Risk \\
\hline \multirow{2}{*}{ II } & \multirow{2}{*}{$0.4-0.5$} & Yes & Low Risk \\
\hline & & No & No Risk \\
\hline \multirow{2}{*}{ III } & \multirow{2}{*}{$0.5-0.7$} & Yes & Medium Risk \\
\hline & & No & No Risk \\
\hline \multirow{2}{*}{ IV } & \multirow{2}{*}{$>0.7$} & Yes & High Risk \\
\hline & & No & No Risk \\
\hline
\end{tabular}

After the stability has been assessed, suggestions to improve the stability are needed to prevent any slope failures. Based on D-Slope system, every risk level has certain suggestions and steps to take (Table 3). Each suggestion is a basic preparation to overcome slope failures in the future.

Table 3: Mitigation suggestions based on risk level of rock slopes [5]

\begin{tabular}{|l|cl|}
\hline Risk Level & \multicolumn{2}{|c|}{ Mitigation Suggestions } \\
\hline No Risk & - & No suggestion \\
\hline \multirow{3}{*}{ Low Risk } & - & Inspection of stream system \\
& - & To plant cover plant on the exposed slopes \\
& - & No immediate steps taken \\
\hline & - & Inspection of stream system \\
Moderate Risk & - & To plant cover plant on the exposed slopes \\
& - & Rock anchor \\
& - & Soil nailing or stone pitching \\
& - & Further inspection proceed \\
\hline & & Immediate actions taken and further \\
& inspection conducted \\
High Risk & - $\quad$ Maintenance works started \\
& - $\quad$ To plant cover plant on the exposed slopes \\
& - $\quad$ To build retaining walls \\
\hline
\end{tabular}

\section{RESULTS AND DISCUSSIONS}

\subsection{Field Observation}

Six (6) slopes are chosen along the Ranau-Tambunan road to Ranau Sports Complex which comprise of Trusmadi Formation and ultrabasic rocks (Figure 2). Field observation is conducted for observation of 13 parameters on field (discontinuities survey) where the appearance of discontinuities such as faults, joints, beddings and fractures are seen; besides the characteristics of the slope itself to assess the stability potential (Table 1).

Slope S1, S2 and S3 consist of interbedding of sandstones and shales of Trusmadi Formation. The sedimentary rocks experienced weathering grade of III to IV with no faults to be found. Number of joints and orientation set are small while the aperture and persistence of joints show within 2 to $4 \mathrm{~mm}$ and less than 4 meters respectively. All slopes received similar rainfall amount of 101 to $300 \mathrm{~mm} /$ month with no water visible and small fragmented rocks on the foot of the slope. However, slope S3 shows higher grade of weathering (grade V- VI) with no significant discontinuities due to its nearly-soil characteristics.

Slope S4, S5 and S6 are ultrabasic rocks which comprise of serpentinized peridotite. All slopes show weathering grade ranges from III to IV with no faults but abundance of joints observed. The spacing of joints is less than $200 \mathrm{~mm}$ with persistence less than 4 meters. The gradient of slope range from $55^{\circ}$ to $70^{\circ}$ with dry condition is indicated by small amount of rainfall received (101 - $300 \mathrm{~mm} /$ month). The minor rock fall showed history of instability of these slopes.
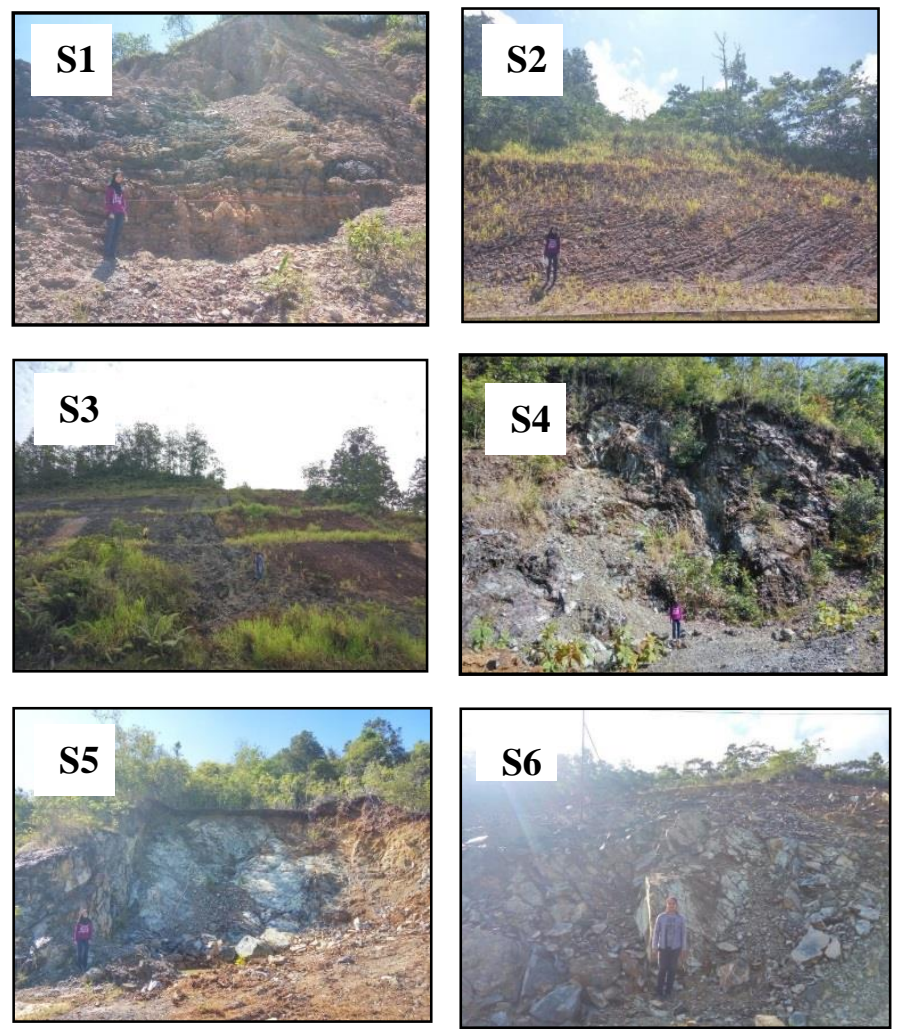

Figure 2: Slopes for research purpose (S1 - S3: Trusmadi Formation; S4 - S6: Ultrabasic rocks)

\subsection{Laboratory Analysis}

Laboratory analysis for this research purpose includes porosity and strength analysis. Rock samples from each slope were collected and cut into cubic size before being tested. These two parameters are additional parameters from modified D-Slope method where the properties of the material are also included to assess the slope failure potential. Porosity analysis is conducted to determine the pore value of rock mass by using calculation method. The appearance of micro-fractures and weathering grade influenced the percentage in the rock samples.

Based on Table 4 below, slopes of Trusmadi Formation (S1, S2 and S3) (sedimentary rocks) show higher porosity range from $3.76 \%-6.23 \%$ compared to slopes of ultrabasic rocks (S4, S5 and S6) which possess only $0.51 \%-2.28 \%$ porosity. This is due to the random arrangement of primary porosity in sedimentary rocks particularly in sandstones which resulted to more pores compared to ultrabasic rocks which have 
compacted texture and gained porosity through the existence of fractures and dissolution of minerals.

Table 4: Porosity value of rock samples from slopes in the study area

\begin{tabular}{|l|l|}
\hline Slopes & Porosity, $\boldsymbol{n}$ (\%) \\
\hline S1 & 4.14 \\
\hline S2 & 6.23 \\
\hline S3 & 3.76 \\
\hline S4 & 1.51 \\
\hline S5 & 0.51 \\
\hline S6 & 2.28 \\
\hline
\end{tabular}

For strength analysis, point load test is conducted where uniaxial compression stress is applied on cubic size of rock samples to test its strength [9]. The calculation and the classification of the strength value is based on (Table 5) [7]. The strength of rocks is influenced by moisture content, density and porosity of rocks. The increment of pores resulted to low density which allows the moisture to fill up the voids. This enables collision between particles which reduces the interlocking thus decreased the strength of rocks. High weathering grade produced fractures thus prepared the failure axis. Based on Table 5, all rocks samples show the classification from moderately strong to really strong with $45.60 \mathrm{MPa}$ to 124.32 MPa value.

Table 5: Strength value of rocks samples and its classification

\begin{tabular}{|l|l|l|}
\hline Slopes & $\begin{array}{l}\text { Uniaxial Strength Value } \\
\text { (MPa) }\end{array}$ & $\begin{array}{l}\text { Classification } \\
\text { (ISRM, 1985) }\end{array}$ \\
\hline S1 & 63.84 & Strong \\
\hline S2 & 59.76 & Strong \\
\hline S3 & 124.32 & Really Strong \\
\hline S4 & 45.60 & Moderately Strong \\
\hline S5 & 113.28 & Really Strong \\
\hline S6 & 78.96 & Strong \\
\hline
\end{tabular}

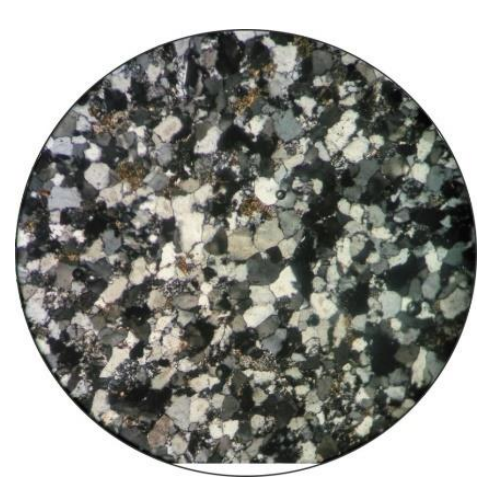

(a) $\mathrm{S} 1$

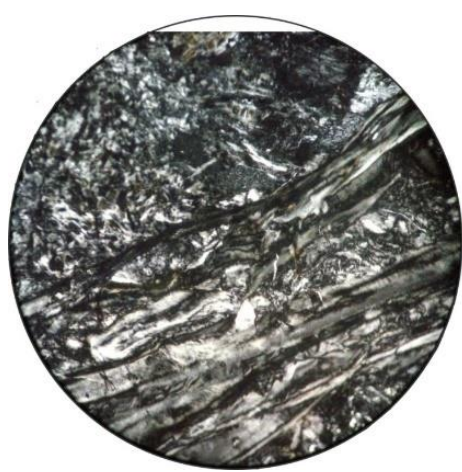

(d) S4

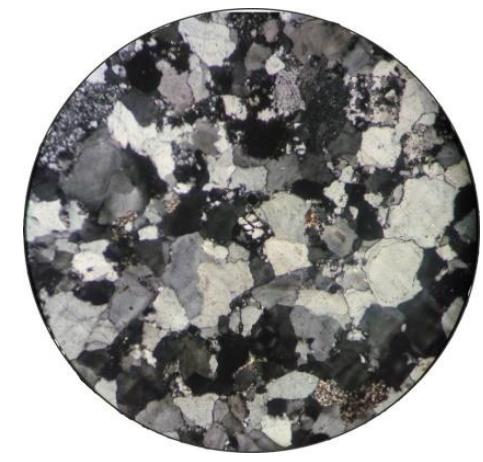

(b) S2

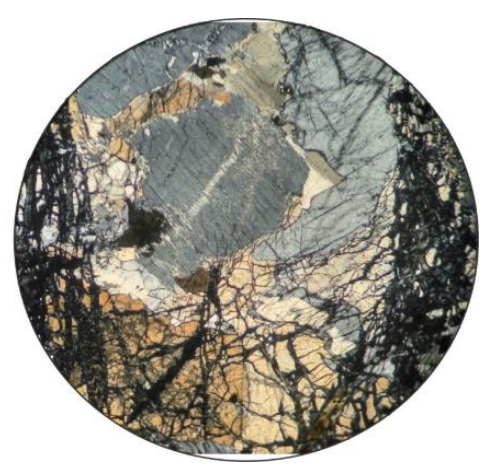

(e) S5

\subsection{Microfabric Observation}

Microfabric analysis is conducted to study the internal of rock's materials. The physical properties of rocks are influenced by its internal characteristics which only can be observed through scanning electron microscope (SEM) and thin section method (polarized microscope observation). By using thin section, micro-petrography and microfractures index can be determined which have been modified from before include into modified D-Slope system for this research [10]. Micropetrography $\left(\mathrm{I}_{\mathrm{mp}}\right)$ index is valued by the ratio of primary minerals to secondary minerals in the rocks, while the micro-fractures $\left(\mathrm{I}_{\mathrm{fr}}\right)$ is determined by the appearance of microfractures between particle (interfractures) and microfractures inside particles (intra-fractures) (Table 6). These index values then will be calculated along with field and laboratory parameters for G-rating purpose.

Table 6: Value of micro-petrography and micro-fractures index of rock samples

\begin{tabular}{|l|l|l|}
\hline Slopes & $\begin{array}{l}\text { Micro-petrography } \\
\text { Index (Imp) }\end{array}$ & $\begin{array}{l}\text { Micro-fractures Index } \\
\left(\mathbf{I}_{\mathrm{fr}}\right)\end{array}$ \\
\hline S1 & 6.5 & 12.7 \\
\hline S2 & 3.3 & 14.0 \\
\hline S3 & 2.8 & 13.3 \\
\hline S4 & 8.2 & 25.3 \\
\hline S5 & 6.8 & 31.3 \\
\hline S6 & 5.1 & 32.0 \\
\hline
\end{tabular}

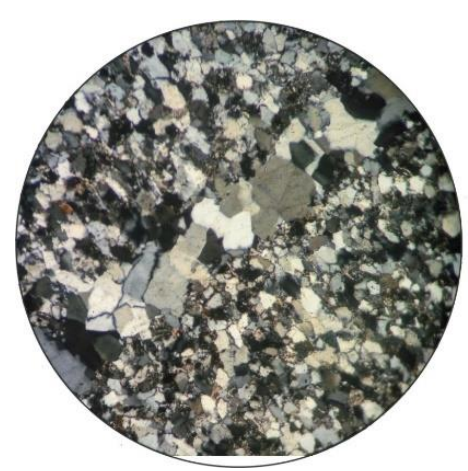

(c) S3

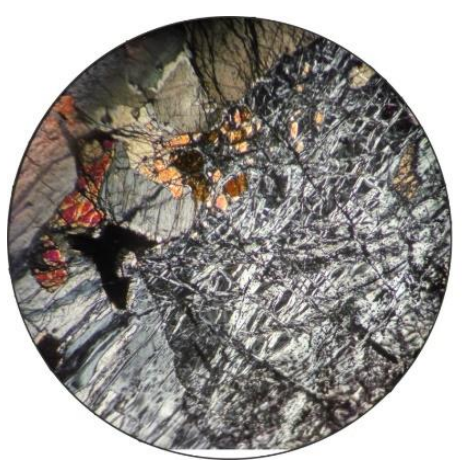

(f) $\mathrm{S} 6$

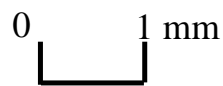

Figure 3: Photomicrographs of sandstones from Trusmadi Formation $(a-c)$ show interlocking of particles produce less microfractures with domination of quartz as primary minerals, while abundance of microfractures can be seen clearly on ultrabasic rocks ( $d-f)$.

Rock samples from slope S1, S2 and S3 are sandstones from Trusmadi Formation which consist of highly compacted arrangement with good interlocking between particles. The samples are dominated by quartz as primary minerals with $63 \%$ to $74 \%$ and the existence of $12.7 \%$ to $14.0 \%$ 
of secondary minerals. The abundance of quartz minerals indicates the resistance of rocks towards weathering process; however still show great presence of intra- and inter-fractures. Therefore, the micro-petrography index for rocks from Trusmadi Formation ranges from 2.8 to 6.5, while the micro-fractures index ranges from 12.7 to 14.0. The microfractures are resulted from interconnecting pores due to the dissolution of soluble minerals rather than voids between particles for sandstones of Trusmadi Formation have tighter inter-locking between particles; hence the amount

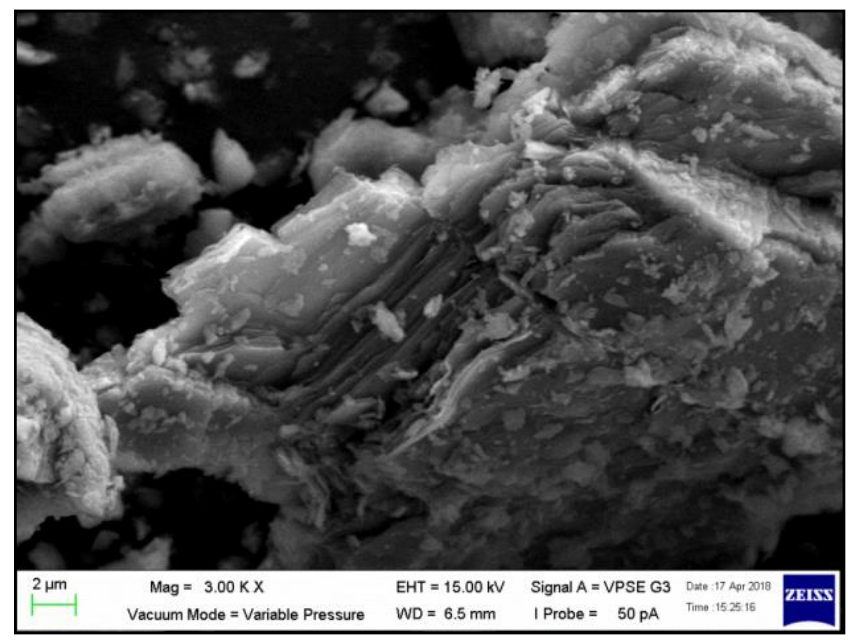

of microfractures is less great than samples from ultrabasic rocks (Figure $3 a-c)$. The ultrabasic rocks from slope S4, S5 and S6 show the appearance of antigorite, olivine and orthopyroxene which contribute around $68 \%$ to $82 \%$ and secondary mineral up to $32 \%$. Figure $3 \mathrm{~d}$-f show significant numbers of microfractures in ultrabasic rocks which resulted to higher micro-fractures index (25.3 - 32.0) compared to sandstones from Trusmadi Formation. Figure 4 below shows the appearance of kaolinite and iron oxides as secondary minerals which appear in the rocks samples.

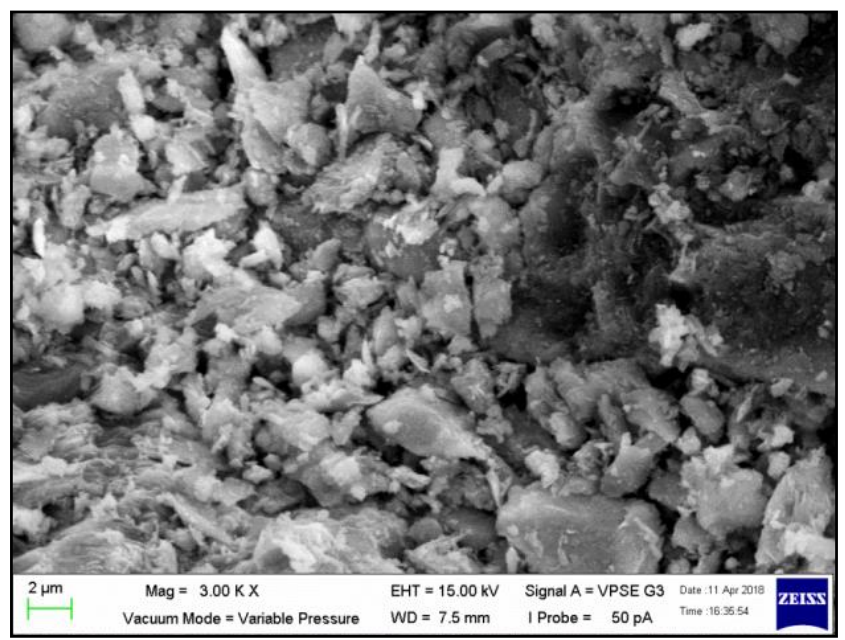

Figure 4: Scanning electron micrographs show the appearance of layering kaolinite (left) and nodules of iron oxide mineral (right) (Magnification 3000X)

\subsection{G-Rating Value Determination}

G-rating value is determined based on data obtained from field and laboratory analysis including microfabric observation. Each parameter is carefully observed and been rated according to its value where the minimum value is 0 while the maximum value is 2 . To obtain the G-rating value, individual parameters are added together before been divided to the total of maximum rating which is 34 . Based on Table 7, slope S1 and S4 show G-rating value higher than 0.4 , while other slopes (S2, S3, S5 and S6) have value less than 0.4 . Small value of G-rating indicates more stable potential compared to higher value rating.

Table 7: Value of G-rating for rock slopes in the study area

\begin{tabular}{|l|l|l|l|}
\hline $\begin{array}{l}\text { Rock } \\
\text { Slopes }\end{array}$ & $\begin{array}{l}\text { Total of } \\
\text { Individual } \\
\text { Rating }\left(\sum \text { Ri }\right)\end{array}$ & $\begin{array}{l}\text { Total of } \\
\text { Maximum } \\
\text { Rating } \\
\left(\sum \text { Rmax }\right)\end{array}$ & $\begin{array}{l}\text { G-Rating Value } \\
\left(\frac{\sum \text { Ri }}{\left.\sum \text { Rmax }\right)}\right)\end{array}$ \\
\hline S1 & 15 & 34 & 0.44 \\
\hline S2 & 13 & 34 & 0.38 \\
\hline S3 & 11 & 34 & 0.32 \\
\hline S4 & 18 & 34 & 0.53 \\
\hline S5 & 7 & 34 & 0.21 \\
\hline S6 & 12 & 34 & 0.35 \\
\hline
\end{tabular}

\subsection{Potential Instability (Kinematic Analysis)}

Potential Instability analysis is a component in D-Slope system to assess the rock slope and was conducted after the G-Rating is done [5]. To obtain the data for potential instability, kinematic analysis is applied to determine the failure type based on the existence of discontinuities. Based on the kinematic analysis of the study area, slope S1, S2, S4, S5 and S6 show either/both wedge and planar failures. These slopes are considered unstable with the potential to fail. Slope S3 however is only determined using G-Rating for there are no significant and clear discontinuities visible on the slope (Table 8).

Table 8: Potential instability analysis for slopes in the study area

\begin{tabular}{|l|l|l|}
\hline Slopes & Type of Failure & Potential Instability \\
\hline S1 & Wedge Failure & Yes \\
\hline S2 & Wedge Failure & Yes \\
\hline S4 & Wedge Failure & Yes \\
\hline S5 & Wedge and Planar Failure & Yes \\
\hline S6 & Wedge and Planar Failure & Yes \\
\hline
\end{tabular}

Planar failure occurs when rock mass is collided along fractured surface axis where the plane of failed discontinuities is parallel with slope face axis. The strike of failed axis must be in range of $20^{\circ}$ from the strike of slope face. Meanwhile, wedge failure occurs when there is any intersection between discontinuities. Rock mass will collide downwards along intersection planes and fall as wedge blocks. All slopes show the characteristics of planar and wedge failure in kinematic analysis but are only considered as failure potential when the discontinuities planes are within the critical zone (Figure 4).
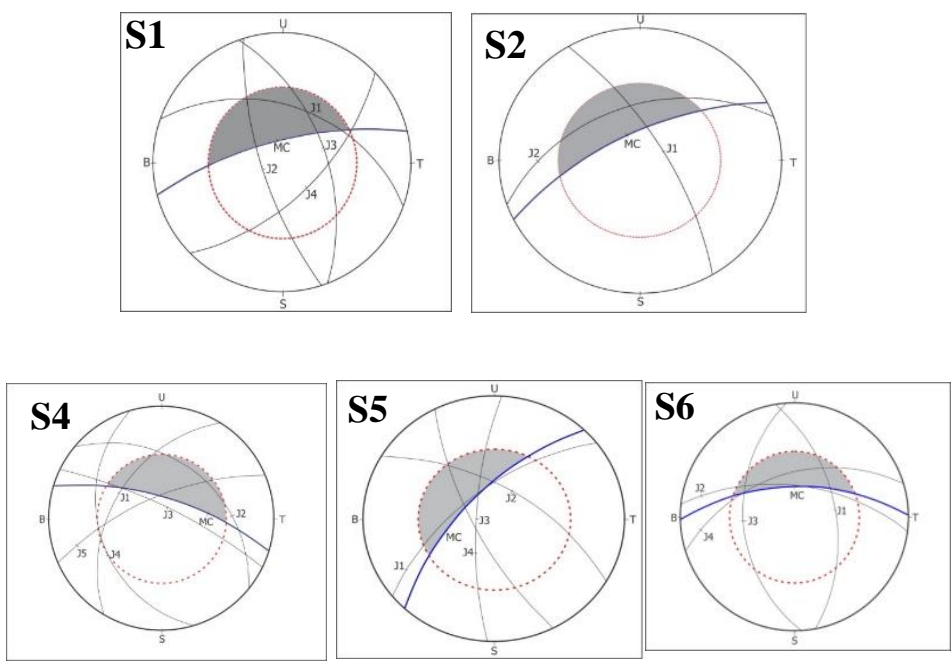

Figure 4: Type of failure on slope in the study area where slope S1, S2 and S3 show wedge failure while S4 and S5 show both wedge and planar failures.

\subsection{D-Slope Analysis}

D-slope analysis is a technique of slope stability assessment which includes two important parameters which are G-rating determination and Instability Potential. Based on these parameters, risk level of the slopes can be identified. Table 9 shows the risk level where all slopes except S3 have potential to fail due to experience wedge and planar failures. However, when combined with assessment of G-rating, only slope S1 and S4 show risk of failure with low and moderate risk, respectively. Slope S2, $\mathrm{S} 3$, S5 and S6 show no risk despite possess failure due to G-rating value are less than 0.4 . 
Table 9: Result of risk level of rock slopes in the study area

\begin{tabular}{|c|c|c|c|c|c|}
\hline Slopes & G-Rating & $\begin{array}{l}\text { Instability } \\
\text { Potential }\end{array}$ & Type of Failures & Risk Level & Category \\
\hline S1 & 0.44 & Yes & Wedge Failure & Low Risk & II \\
\hline S2 & 0.38 & Yes & Wedge Failure & No Risk & $\mathrm{I}$ \\
\hline S3 & 0.32 & - & - & No Risk & $\mathrm{I}$ \\
\hline S4 & 0.53 & Yes & Wedge Failure & Moderate Risk & III \\
\hline S5 & 0.21 & Yes & $\begin{array}{l}\text { Wedge and Planar } \\
\text { Failure }\end{array}$ & No Risk & I \\
\hline S6 & 0.35 & Yes & $\begin{array}{l}\text { Wedge and Planar } \\
\text { Failure }\end{array}$ & No Risk & I \\
\hline
\end{tabular}

\subsection{Mitigation Suggestions}

Based on a study, there are suitable mitigation methods to prevent slope failure to occur (Table 3) [5]. Each proposed mitigation methods are depending on the risk level achieved by the slopes.

Slope S4 is classified as moderate risk which requires further inspection of the slope and the stream system of the area. Planting a vegetation on exposed area of the slope is also suggested other than proposed rock anchor and soil nailing method to prevent the slope failure. As for slope S1 which is low risk classification, no immediate action needed and it is suggested to make inspection on the stream system and vegetation on the exposed area to reduce the instability potential. As for other slopes, no suggestion is needed for there is no risk of slope failure to occur (Table $10)$.

Table 10: Mitigation suggestions proposed based on the risk level

\begin{tabular}{|c|c|c|c|}
\hline Slopes & Risk Level & Category & Mitigation Suggestions \\
\hline S1 & Low Risk & II & $\begin{array}{l}\text { - To inspect the stream } \\
\text { system } \\
\text { - To plant vegetation on the } \\
\text { exposed area of the slope } \\
\text { - No immediate action } \\
\text { needed }\end{array}$ \\
\hline S2 & No Risk & I & No suggestion \\
\hline S3 & No Risk & I & No suggestion \\
\hline S4 & $\begin{array}{l}\text { Moderate } \\
\text { Risk }\end{array}$ & III & $\begin{array}{l}\text { - To inspect the stream } \\
\text { system } \\
\text { - To plant vegetation on the } \\
\text { exposed area of the slope } \\
\text { - Rock anchoring } \\
\text { - Soil nailing or stone } \\
\text { pitching } \\
\text { - Further action required }\end{array}$ \\
\hline S5 & No Risk & I & No suggestion \\
\hline S6 & No Risk & I & No suggestion \\
\hline
\end{tabular}

\section{CONCLUSION}

Modified D-Slope comprised of G-rating determination and Potential Instability using kinematic analysis. Additional of laboratory analysis (porosity and strength analysis) and microfabric observation (micropetrographic and micro-fractures index) are conducted to assess the internal properties of the slope, besides the field observations (geological parameters, hydrogeological parameters and slope characterization) for the exterior of slope's potential of failure.

G-rating determination show slope S1 and S4 have value more than 0.4 ( 0.44 and 0.53 respectively), while other slopes have value less than 0.4 which indicates no risk of failure. Slope S1, S2 and S4 show wedge failure while slope S5 and S6 show both wedge and planar failures. This indicates the potential instability of all slopes. Based on modified D-Slope analysis, slope S4 is classified as Moderate Risk (III), slope S1 as Low Risk (II) and other slopes as No Risk (I).

Mitigation suggestions are depends on the risk level of the slopes. Slope S4 is suggested to have rock anchor or soil nailing as further actions are required on this level; while slope S4 is suggested to inspect the stream system and plant vegetation on the exposed area of the slope as no immediate actions needed. Other slopes (S2, S3, S5 and S6) have no suggestion for mitigation as been assessed as level I.

\section{REFERENCES}

[1] Rodeano, R. 2004. Study of Mass Movement along Bundu Tuhan to Kundasang Highway, Sabah, Malaysia. Disertasi Sarjana Sains. Universiti Malaysia Sabah, Kota Kinabalu.

[2] Turner, A.K., Schuster, R.L. 1996. Landslides: Investigation and Mitigation. Transportation Reseacrh Board, National Research Council, Special Report. National Academy Press, Washington DC, 247.

[3] Tating, F.F. 2003. The Geology and Landslide in the Northern Kota Kinabalu, Sabah, Malaysia. Graduate School of Science and Technology, Kumamoto University, Japan.

[4] Komoo, I., Akhir, J.M. 1990. Kamus Istilah Geologi Asas. Universiti Kebangsaan Malaysia, Bangi

[5] Husaini, O. 2002. Development of Risk and Expert Systems for Cut Slopes. PhD Thesis. Universiti Putra Malaysia.

[6] Jacobson, G. 1970. Gunung Kinabalu area, Sabah, Malaysia: Explanation of part of Sheets 5-116-3 and 6-116-15, Report 8. Geological Survey Malaysia, Kuching

[7] International Standard of Rock Mechanics (ISRM). 1985. Suggested Methods for Determining Point Load Strength. ISRM Commission on Standardization of Laboratory and Field Test. Int. Journal of Rock Mech. Min. Sci. 16. 141-156.

[8] Bujang, K.H., Ali, F., David, H.B., Harwant, S., Omar, H. 2008. Landslide in Malaysia: Occurrence Assessment Analysis and Remediation. UPM Press, Serdang, Selangor.

[9] Bienieski, Z.T. 1975. The Point Load Test in Geotechnical Practice. Engineering Geology, 9 (1), 1-11.

[10] Fookes, P.G., Dearclan, W.R., Franklin, I.A. 1971. Some Engineering Aspects of Rocks Weathering. Quarterly Journal of Engineering Geology, 4, 139-185.

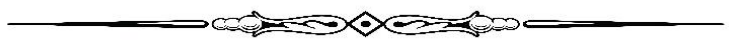

